\title{
Rise to Power: A Case Study of Male Fecal Androgen and Cortisol Levels before and after a Non-Aggressive Rank Change in a Group of Wild White-Faced Capuchins (Cebus capucinus)
}

\author{
Valérie A.M. Schoof ${ }^{a} \quad$ Katharine M. Jack $^{a}$ Sarah D. Carnegie ${ }^{b}$ \\ a Department of Anthropology, Tulane University, New Orleans, La., USA; \\ ${ }^{b}$ Department of Anthropology, University of Calgary, Calgary, Alta., Canada
}

\section{Key Words}

Rank acquisition - Dominance - Reproduction - Endocrinology • Fecal hormones • Male competition

\begin{abstract}
We examined fecal androgen and cortisol levels in three adult male white-faced capuchin monkeys (Cebus capucinus) before and after a non-aggressive rank increase in one habituated group residing in the Santa Rosa Sector of the Área de Conservación Guanacaste, Costa Rica. Fecal samples $(n=116)$ were collected opportunistically between July 2006 and July 2007. Alpha males had higher mean androgen levels than subordinates, and acquisition of the alpha position was linked to an immediate increase in mean androgens. Cortisol levels also increased in the alpha male after acquisition of his new rank, though this increase was delayed relative to the change in rank. These results indicate that, during a non-aggressive rank change, androgen and cortisol levels in male white-faced capuchins are physiological responses to dominance rank, rather than precursors that facilitate rank acquisition.

Copyright $\odot 2012$ S. Karger AG, Basel
\end{abstract}

\section{Introduction}

Group-living males compete for mates directly, in the form of challenges for immediate access to females, or indirectly, via the dominance hierarchy and the associated reproductive benefits of high rank (i.e. priority of access to mates; reviewed in van Hooff [2004]). Androgens, and specifically testosterone, are associated with facilitation of aggression in a reproductive context, including aggression that occurs during challenges for access to mates or territory, and during the formation of dom-

\begin{tabular}{ll}
\hline KARGER & ๑ 2012 S. Karger AG, Basel \\
Fax +41 61 306 12 34 & 0015-5713/11/0826-0299\$38.00/0 \\
$\begin{array}{l}\text { E-Mail karger@karger.ch } \\
\text { www.karger.com }\end{array}$ & $\begin{array}{l}\text { Accessible online at: } \\
\text { www.karger.com/fpr }\end{array}$
\end{tabular}

Valérie A.M. Schoof

Department of Anthropology, Tulane University 101 Dinwiddie Hall, 6283 St-Charles Avenue New Orleans, LA 70118 (USA)

Tel. +1 504343 0895, E-Mail vschoof@tulane.edu 
inance relationships (challenge hypothesis [Wingfield et al., 1990]). Therefore, it is not surprising that dominant males in many non-human primate species have higher androgens than subordinates when male-male competition is high, such as throughout the mating season (Leontopithecus rosalia [Bales et al., 2006]; Lemur catta [Gould and Ziegler, 2007]), during periods of social instability (Papio anubis [Sapolsky, 1983]; Pan paniscus [Marshall and Hohmann, 2005]), or when the timing of challenges for mates or the threat of infanticide is unpredictable (Propithecus verreauxi [Kraus et al., 1999]; Pan troglodytes [Muehlenbein et al., 2004; Muller and Wrangham, 2004a]; Papio hamadryas ursinus [Beehner et al., 2006]; Mandrillus sphinx [Setchell et al., 2008]).

In species where rank-based differences in androgens have been observed, the timing of dominance-related changes in androgens appears to be mediated by the manner in which males acquire their dominance rank. For example, an increase in androgens occurs prior to [Wickings and Dixson, 1992; Beehner et al., 2006] or during the rank acquisition process [Alberts et al., 1992; Brockman et al., 1998; Beehner et al., 2006] when elevated androgens facilitate an increase in aggressive behavior or competitive ability. When rank acquisition is not associated with elevated aggression, an increase in androgens is expected only after the increase in dominance rank. However, if no rank-based differences are known, changes in the dominance hierarchy are not expected to coincide with specific changes in androgens.

Glucocorticoids (GCs) and the metabolite cortisol (CORT) mediate the homeostatic responses to stressors, both social and environmental (reviewed in Sapolsky [2005]). The relationship between dominance rank and GCs (or CORT) is also variable, and is associated with the relative amount of stress experienced by dominant and subordinate individuals [Abbott et al., 2003; Goymann and Wingfield, 2004; Sapolsky, 2005]. Changes in the male dominance hierarchy and social instability can be stressful but may differentially affect males of different ranks. Bergman et al. [2005] found that in chacma baboons all group males experienced elevated GC levels during times of social change and instability (e.g. rank changes and immigrations). However, Sapolsky [1993] noted that in several species dominant males had higher GCs than subordinates during unstable, but not stable, periods. In chimpanzees, however, dominant males have elevated CORT during stable periods [Muller and Wrangham, 2004b]. Where males have persistent rank-based differences in GC levels, the timing of changes in the pattern of GCs is unclear. Sapolsky [2005] suggests that, in relation to GCs at least, the hormonal patterns associated with a particular rank occur after, rather than prior to, dominance rank acquisition. This suggests that GC patterns reflect dominance rank, and that behaviors associated with rank drive the association with GC, rather than GC driving the behavior [Sapolsky, 2005, p. 398].

We examined fecal androgen and cortisol (fCORT) levels in three males residing in one habituated group of capuchins (Los Valles group), following the peaceful immigration of a subordinate male (CY, on July 21, 2006) and his subsequent rank increase (described in Carnegie et al. [2011a]). White-faced capuchins are small New World monkeys that live in groups of multiple related females, their offspring and immigrant males. Alpha males sire the majority of offspring (up to 89\% [Jack and Fedigan, 2006; Muniz et al., 2010]), are the most vigilant [Rose and Fedigan, 1995], are the most involved in intergroup encounters and takeovers [Perry, 1996] and have the highest androgen levels within their group [Schoof and Jack, 2009]. Rank-based differences in androgens do not appear to be associated with aggression among co- 
resident males, as these relationships are tolerant in nature [Jack, 2003]. Although male capuchins are extremely transitory in our study population [Jack and Fedigan, 2004], this is the first study to document hormone changes associated with rank changes in this species (and in the genus Cebus).

\section{Materials and Methods}

Study Site and Subjects

This study took place in the Santa Rosa Sector of the Área de Conservación Guanacaste, Costa Rica, between August and November 2006, and February and July 2007 (for additional information about the Santa Rosa capuchin project and study cite see Fedigan and Jack [2012]). At the beginning of the study period, the group contained three adult males, five adult females, three natal juvenile males and four juvenile females. To examine possible changes in hormone levels in relation to rank change, we divided the samples into 4 phases.

In phase 1 (before rank change), July 2006, CY joined the group as a subordinate. The group included the alpha male CB (joined group as subordinate in March 2004 and had been alpha since May 1, 2006) and subordinate male WW (joined group in May 2004). In phase 2 (rank change), CB disappeared and CY became alpha male without aggression. In phase 3 (dry season), no aggression was observed between CY, who had been alpha for 4 months, and WW, who remained subordinate. In phase 4 (early wet season), CY had been alpha male for 7.5 months and WW remained subordinate. Phases 3 and 4 were separated because an earlier study [Schoof and Jack, 2009] found that male capuchins have higher androgens in the dry season relative to the early wet season.

Data Collection and Analysis

We collected fresh fecal samples opportunistically from CB, CY and WW between July and November $2006(n=62)$, and once per week from CY and WW from February to July 2007 $(\mathrm{n}=54)$. We collected fecal samples within 5 minutes of defecation, and initial processing in the field followed Carnegie et al. [2011a]. Samples were analyzed at the Wisconsin National Primate Research Center by V.A.M. Schoof. Fecal samples were eluted from the SPE cartridges and subsequently analyzed for androgens and CORT by enzyme immunoassay. All samples and standard curves were run in duplicate. Research complied with protocols approved by the Área de Conservación Guanacaste and the Tulane University IACUC, conformed to the ethical guidelines of the American Society of Primatologists, and adhered to the legal requirements of Costa Rica and the USA.

\section{Methodological Validation}

Mean intra- and interassay coefficients of variation for androgens were 5.5 and $17.9 \%$ for the low pool, and 7.4 and $12.4 \%$ for the high pool, respectively. Mean intra- and interassay coefficients of variation for fCORT were 6.2 and $14.0 \%$ for the low pool, and 2.7 and $6.0 \%$ for the high pool, respectively. Mean percent accuracy (the degree to which the assay actually measures the steroid in a known pool) was high for both androgens $(109.05 \pm 2.79 \%, \mathrm{n}=8)$ and fCORT $(115.48 \pm 2.27 \%, \mathrm{n}=6)$. Additionally, the percent bound values from the pooled samples paralleled the percent bound values of the standard curve for all hormones, and there were no differences in their slopes (androgens: $\mathrm{t}_{28}=0.841, \mathrm{p}>0.05, \mathrm{n}=8$; fCORT: $\mathrm{t}_{21}=0.066, \mathrm{p}>0.05, \mathrm{n}=$ 7). Finally, Lynch et al. [2002] report HPLC fractions of testosterone and CORT to have very low cross-reactivities for Cebus apella.

Physiological validation of fecal androgen is supported by Lynch et al. [2002], who report an increase in testosterone and fCORT in males during the period of peak sexual activity. Furthermore, Schoof and Jack [2009] report that alpha males have significantly higher levels of androgens than subordinate males. fCORT has been validated in female capuchins, where research indicates an increase in fCORT in response to stressful events [Carnegie et al., 2011a]. 


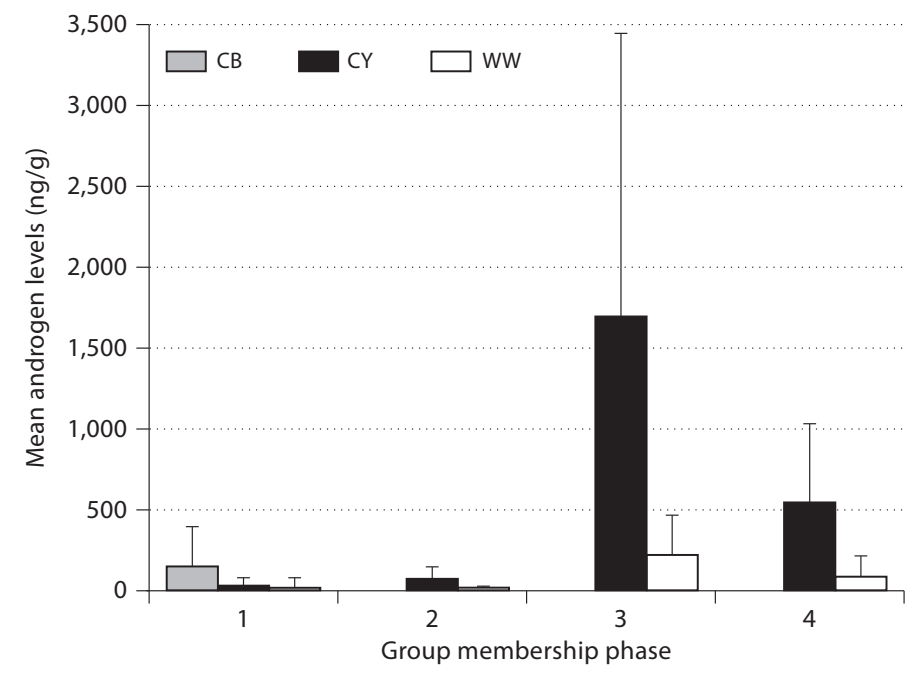

Fig. 1. Androgen levels (means \pm SE) for males during 4 different phases of group membership. Phase 1: before rank change, $\mathrm{CB}$ is alpha male; phase 2: rank change, $\mathrm{CY}$ becomes and remains alpha male for the remainder of the study period; phase 3: dry season; phase 4: early wet season.

\section{Statistics}

All androgen and fCORT values were $\log _{10}$ transformed to meet the assumption of normality. We used ANOVA and Hochberg's GT2 post hoc test for unequal sample sizes (equal variances) to compare hormone levels for all three males during phase 1 (two-tailed). In phases 2-4, we used Satterthwaite's t test to account for the unequal variances among males CY and WW (two-tailed).

\section{Results}

Male fecal androgen and fCORT levels are associated with changes in dominance rank in white-faced capuchins. In the present study, we report on the timing of fecal androgen and fCORT changes during a non-aggressive rank increase. In July 2006, subordinate immigrant male CY began traveling, feeding and sleeping with members of the Los Valles group. Though CY was peripheral at this time, he would occasionally foray into the center of the group with no overt aggression from alpha male CB. Subordinate resident male WW was affiliative with CY, and often moved to the periphery of the group to be in proximity to him. Resident alpha male CB disappeared from the group in October 2006, for unknown reasons, and has not been seen again. After CB's disappearance, CY peacefully took over the alpha role with no apparent opposition from subordinate resident WW. 


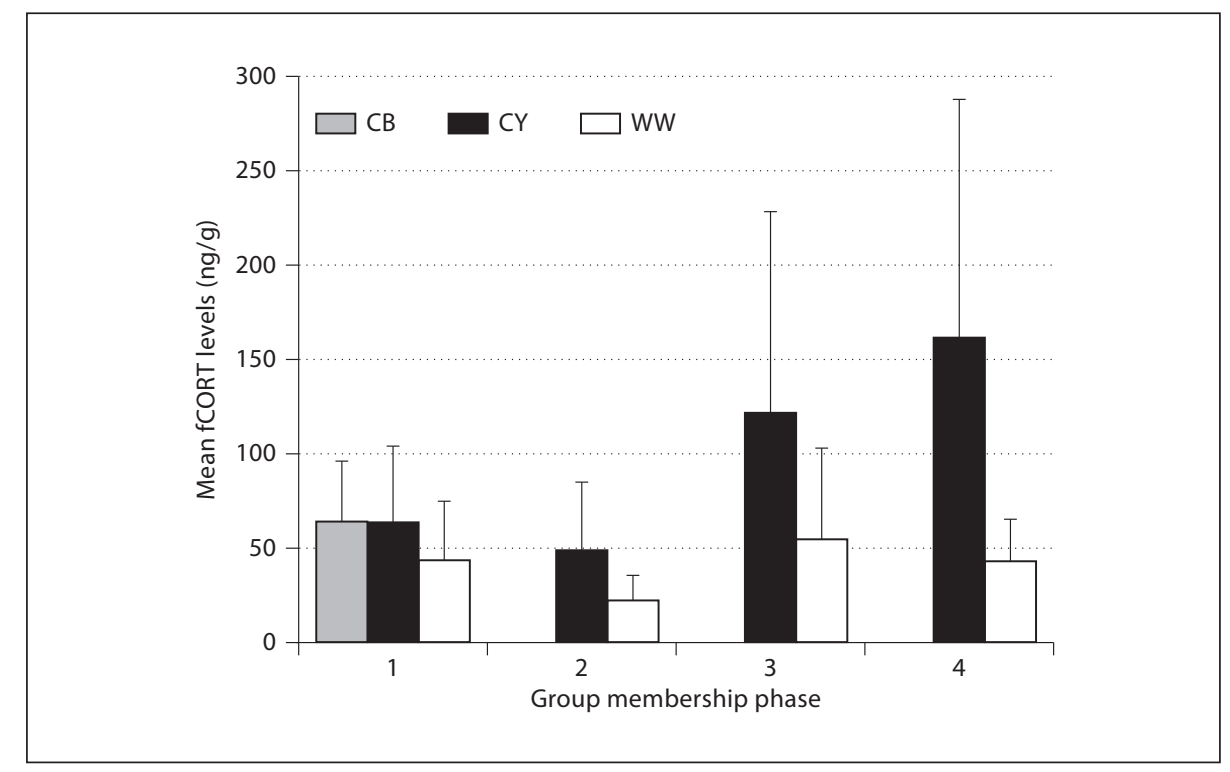

Fig. 2. fCORT levels (means \pm SE) for males during 4 different phases of group membership. Phase 1: before rank change, $\mathrm{CB}$ is alpha male; phase 2: rank change, $\mathrm{CY}$ becomes and remains alpha male for the remainder of the study period; phase 3: dry season; phase 4: early wet season.

\section{Androgens}

During phase 1, mean androgen levels were significantly different among the three males $(\mathrm{F}=21.684$, d.f. $=2, \mathrm{p}<0.001)$ : post hoc tests indicate that the resident alpha male CB had significantly higher androgen levels than both the immigrant subordinate $\mathrm{CY}(\mathrm{t}=1.120, \mathrm{p}<0.001)$ and resident subordinate $\mathrm{WW}(\mathrm{t}=1.207, \mathrm{p}<$ $0.001)$, but there was no difference between the two subordinate males $(t=0.874, p=$ 0.998). After CY's rise to alpha status (following the disappearance of resident alpha male $\mathrm{CB}$ ), the immigrant male $\mathrm{CY}$ had significantly higher mean androgen than the resident male $\mathrm{WW}$ in all three subsequent phases (phase 2: $\mathrm{t}=2.51$, d.f. $=5.144, \mathrm{p}=$ 0.05 ; phase $3: t=3.01$, d.f. $=28.121, p=0.006$; phase $4: t=3.21$, d.f. $=16.765, p=0.005$; fig. 1).

\section{Cortisol}

Mean fCORT was significantly different among males during phase $1(\mathrm{~F}=$ 4.223, d.f. $=2, \mathrm{p}=0.020$ ); the resident alpha male CB had higher mean fCORT than the resident subordinate male WW $(t=0.252, \mathrm{p}=0.018)$, but not more than the immigrant subordinate male CY $(t=0.051, \mathrm{p}=0.974)$. Also, fCORT did not differ between the two subordinate males in phase $1(t=0.201, p=0.390)$. In phase 2 , there was no difference in fCORT levels between the immigrant alpha male CY and resident subordinate male $\mathrm{WW}(\mathrm{t}=1.26$, d.f. $=6.543, \mathrm{p}=0.25)$. However, mean fCORT was higher in CY than in WW in both phase $3(t=2.64$, d.f. $=31.061, p=0.01)$ and phase $4(\mathrm{t}=3.71$, d.f. $=11.93, \mathrm{p}=0.003$; fig. 2$)$. 


\section{Discussion}

Consistent with previous research [Schoof and Jack, 2009], androgen levels were higher in alpha than in subordinate males. The alpha male CB, who disappeared from the group two months into our study, had significantly higher androgen levels than the two subordinate males (CY and WW). The androgen levels of these two subordinate males did not differ from one another at this time (phase 1). However, once CY became alpha male, he had significantly higher mean androgen levels than subordinate WW (phase 2), a difference which persisted for the remainder of the study period (phases 3 and 4 ).

The absence of observed within-group aggression over the alpha position is consistent with the lack of difference in mean androgen between subordinate WW and CY prior to CY's rise to alpha status. The pattern of androgen increase following a rise in dominance rank (specifically for the alpha male) is consistent with reports for free-ranging sifakas [Brockman et al., 1998] and mandrills [Setchell and Dixson, 2001], as well as captive squirrel monkeys [Mendoza et al., 1979], rhesus macaques [Rose et al., 1975], and talapoin monkeys [Eberhardt et al., 1980].

Both the former alpha male CB and immigrant subordinate CY had higher fCORT than subordinate male WW, but there was no difference between CB and CY. Elevations in fCORT levels prior to becoming alpha could be linked with increased metabolic demands in preparation for aggressively taking over the alpha position; however, this is improbable because CY did not aggressively overthrow male CB (based on our observations). A more likely explanation is that CY's heightened fCORT levels were in response to his recent immigration into the group, and his increased spatial proximity to unknown individuals may have been stressful to him, as has also been observed in newly immigrant chacma baboons and sifakas [Bergman et al., 2005; Brockman et al., 2009]. While CY's fCORT did not increase immediately following his rise to alpha male (phase 2), it did increase in phases 3 and 4 to levels significantly greater than subordinate male WW. In white-faced capuchins, infanticide is frequently associated with changeovers in male group membership and dominance status [Fedigan, 2003]. New alpha males can be potential sires of group infants following approximately 5.5 months in that position (average gestation length [Carnegie et al., 2011b]). CY became alpha male in early October 2006; therefore, we expect any infants he sired to be born after early March 2007. CY's fCORT was significantly higher during phases 3 and 4 (February through July 2007), suggesting that psychosocial stress and metabolic demands increased only once he had potential offspring in the group. However, it is important to remember that GCs serve multiple functions other than those discussed in the present article, and changes in the levels of fCORT observed may be unrelated to social stress.

Based on the timing of the hormonal changes observed in this study, it appears that physiological changes in male white-faced capuchins follow changes in dominance rank at least in cases where these changes are peaceful. However, male whitefaced capuchins can gain alpha status in other ways, and it is possible, in cases of aggressive group takeover [Fedigan and Jack, 2004; Jack and Fedigan, 2004] or aggressive within-group rank reversal [Perry, 1998], that incoming (or upcoming) males already display androgen levels characteristic of dominant males. Alberts et al. [1992] report that an immigrant yellow baboon male with high rates of aggression had very high GC levels and testosterone values were three times that of the resident 
male average. Sifaka males (P. verreauxi) who transferred aggressively into new groups had higher testosterone levels than those who entered peacefully [Brockman et al., 2001]. However, regardless of the presence or absence of aggression, all immigrating male sifakas had elevated testosterone levels, though they decreased a few days after immigration [Brockman et al., 2001, 2009].

It is interesting that in our current study, the alpha male CB had relatively low androgen levels compared to $\mathrm{CY}$ once he was established as the group's alpha male and also in comparison to other alpha males we have examined in our study population (BG: $914.9 \pm 166.3$; AT: $311.4 \pm 69.2$ [Schoof and Jack, unpubl. results]). However, CB had been a subordinate male in Los Valles for over two years prior to peacefully inheriting the alpha male position following the desertion of the group by the alpha and beta males (who took over a neighboring study group). CB's inheritance of the alpha position preceded CY's immigration into Los Valles by less than three months. Indeed, it was only in the month prior to CY's immigration that Los Valles group members started directing clear behaviors towards CB that were indicative of his status as the group's alpha male (e.g. gargles).

Male white-faced capuchins can increase their dominance rank aggressively, via the takeover of a group (where invading male coalitions forcibly evict resident males [Fedigan and Jack, 2004; Jack and Fedigan, 2004]) or during a rank reversal within a social group (where resident subordinate males challenge higher-ranked males [Perry, 1998]). Males can also increase their dominance rank peacefully by waltzing in (where males assume residency in a group that has been abandoned by all adult males [Fedigan and Jack, 2004]) or via a peaceful increase in rank when higherranked resident males emigrate or die [Jack and Fedigan, 2004]. The data presented here indicate that there may be some lag time involved in the androgen response to the attainment of alpha male status in this species; although CY's androgen was significantly higher than WW's almost immediately following his rise to alpha status, CY's androgens skyrocketed within a few months following the rank change (fig. 1). Previous research demonstrates that males have lower androgens in the early wet season compared to the dry season [Schoof and Jack, 2009], and preliminary data suggest that androgens may continue to decline as the wet season progresses [Schoof, unpubl. data]. We will continue to address these questions as part of a long-term analysis of male dominance rank and dispersal in this species.

\section{Acknowledgments}

We are grateful to Roger Seguro-Blanco for granting permission to conduct this study in the Área de Conservación Guanacaste, to A. Childers, Z. King, C. Sheller, A. Petrosoniak, G. McCabe and A. Biasin for assistance in field data collection, and D. Wittwer and T. Ziegler for providing valuable training and guidance in performing the hormone analyses [the NIH provides partial support to the Wisconsin National Primate Research Center (RR000167) to help support the cost of analysis]. Research support and conference funding were available from the Fonds Québecois de la Recherche sur la Nature et les Technologies (V.A.M.S.), Tulane University's Graduate Student Studies Association (V.A.M.S.), Provost's office (V.A.M.S.), Research Enhancement Fund (K.M.J.), Department of Anthropology (K.M.J.) and the Stone Center for Latin American Studies (K.M.J.), the National Science and Engineering Research Council of Canada (S.D.C.), Alberta Ingenuity Fund (S.D.C.) and the International Society of Primatologists (S.D.C.). 


\section{References}

-Abbott DH, Keverne EB, Bercovitch FB, Shively CA, Mendoza SP, Saltzman W, Snowdon CT, Ziegler TE, Banjevic M, Garland T Jr, Sapolsky RM (2003). Are subordinates always stressed? A comparative analysis of rank differences in cortisol levels among primates. Hormones and Behavior 43: 67-82.

-Alberts SC, Sapolsky RM, Altmann J (1992). Behavioral, endocrine, and immunological correlates of immigration by an aggressive male into a natural primate group. Hormones and Behavior 26: 167-178.

Bales KL, French JA, McWilliams J, Lake RA, Dietz JM (2006). Effects of social status, age, and season on androgen and cortisol levels in wild male golden lion tamarins (Leontopithecus rosalia). Hormones and Behavior 49: 88-95.

- Beehner J, Bergman T, Cheney D, Seyfarth R, Whitten P (2006). Testosterone predicts future dominance rank and mating activity among male chacma baboons. Behavioral Ecology and Sociobiology 56: 469-479.

Bergman TJ, Beehner JC, Cheney DL, Seyfarth RM, Whitten PL (2005). Correlates of stress in freeranging male chacma baboons, Papio hamadryas ursinus. Animal Behavior 70: 703-713.

-Brockman DK, Cobden AK, Whitten PL (2009). Birth season glucocorticoids are related to the presence of infants in sifaka (Propithecus verreauxi). Proceedings of the Royal Society London, Series B 276: $1855-1863$.

Brockman DK, Whitten PL, Richard AF, Benanader B (2001). Birth season testosterone levels in male Verreaux's sifaka, Propithecus verreauxi: insights into socio-demographic factors mediating seasonal testicular function. Behavioral Ecology and Sociobiology 49: 117-127.

- Brockman DK, Whitten PL, Richard AF, Schneifer A (1998). Reproduction in free-ranging male Propithecus verreauxi: the hormonal correlates of mating and aggression. American Journal of Physical Anthropology 105: 137-151.

-Carnegie SD, Fedigan LM, Ziegler TE (2011a). Social and environmental factors affecting fecal glucocorticoids in wild, female white-faced capuchins (Cebus capucinus). American Journal of Primatology 73: 1-9.

- Carnegie SD, Fedigan LM, Melin AD (2011b). Reproductive seasonality in female capuchins (Cebus capucinus) in Santa Rosa (Area de Conservacion Guanacaste), Costa Rica. International Journal of Primatology 32: 1076-1090.

Eberhardt JA, Keverne EB, Meller RE (1980). Social influences on plasma testosterone levels in male talapoin monkeys. Hormones and Behavior 14: 247-266.

Fedigan LM (2003). Impact of male takeovers on infant deaths, births and conceptions in Cebus capucinus at Santa Rosa, Costa Rica. International Journal of Primatology 24: 723-741.

Fedigan LM, Jack KM (2001). Neotropical primates in a regenerating Costa Rican dry forest: a comparison of howler and capuchin population patterns. International Journal of Primatology 22: 689-713.

Fedigan LM, Jack KM (2004). The demographic and reproductive context of male replacements in Cebus capucinus. Behaviour 141: 755-775.

Fedigan LM, Jack KM (2012). Tracking monkeys in Santa Rosa: lessons from a regenerating tropical dry forest. In Long-Term Field Studies of Primates (Kappeler PM, Watts D, eds.), pp 165-184. Berlin, Springer.

Gould L, Ziegler TE (2007). Variation in fecal testosterone levels, inter-male aggression, dominance rank and age during mating and post-mating periods in wild adult male ring-tailed lemurs (Lemur catta). American Journal of Primatology 69: 1325-1339.

Goymann W, Wingfield JC (2004). Allostatic load, social status and stress hormones: the costs of social status matter. Animal Behavior 67: 591-602.

Jack KM (2003). Explaining variation in affiliative relationships among male white-faced capuchins (Cebus capucinus). Folia Primatologica 74: 1-16.

-Jack KM, Fedigan LM (2004). Male dispersal patterns in white-faced capuchins, Cebus capucinus. Part 2: Patterns and causes of secondary dispersal. Animal Behavior 67: 771-782.

Jack KM, Fedigan LM (2006). Why be alpha male? Dominance and reproductive success in wild whitefaced capuchins (Cebus capucinus). In New Perspectives in the Study of Mesoamerican Primates: Distribution, Ecology, Behavior and Conservation (Estrada A, Garber P, Luecke L, Pavelka MSM, eds.), pp 367-386. Amsterdam, Kluwer Publishing.

Kraus C, Heistermann M, Kappeler PM (1999). Physiological suppression of sexual function in subordinate males: a subtle form of intrasexual competition among male sifakas (Propithecus verreauxi)? Physiology and Behavior 66: 855-861.

Lynch JW, Ziegler TE, Strier KB (2002). Individual and seasonal variation in fecal testosterone and cortisol levels of wild male tufted capuchin monkeys, Cebus apella nigritus. Hormones and Behavior 41: $275-287$. 
Marshall AJ, Hohmann G (2005). Urinary testosterone levels of wild male bonobos (Pan paniscus) in the Lomako Forest, Democratic Republic of Congo. American Journal of Primatology 65: 87-92.

Mendoza SP, Coe CL, Lowe EL, Levine S (1979). The physiological response to group formation in adult male squirrel monkeys. Psychoneuroendocrinology 3: 221-229.

Muehlenbein MP, Watts DP, Whitten PL (2004). Dominance rank and fecal testosterone levels in adult male chimpanzees (Pan troglodytes schweinfurthii) at Ngogo, Kibale National Park, Uganda. American Journal of Primatology 64: 71-82.

Muller MN, Wrangham RW (2004a). Dominance, aggression and testosterone in wild chimpanzees: a test of the 'challenge hypothesis'. Animal Behaviour 67: 113-123.

-Muller MN, Wrangham RW (2004b). Dominance, cortisol and stress in wild chimpanzees (Pan troglodytes schweinfurthii). Behavioral Ecology and Sociobiology 55: 332-340.

Muniz L, Perry S, Manson JH, Gilkenson H, Gros-Louis J, Vigilant L (2010). Male dominance and reproductive success in wild white-faced capuchins (Cebus capucinus) at Lomas Barbudal, Costa Rica. American Journal of Primatology 72: 1118-1130.

- Perry S (1996). Intergroup encounters in wild white-faced capuchins (Cebus capucinus). International Journal of Primatology 17: 309-330.

- Perry S (1998). A case report of a male rank reversal in a group of wild white-faced capuchins. Primates 39: 51-70.

Rose LM, Fedigan LM (1995). Vigilance in white-faced capuchins, Cebus capucinus, in Costa Rica. Animal Behaviour 49: 63-70.

Rose RM, Bernstein IS, Gordon TP (1975). Consequences of social conflict on plasma testosterone levels in rhesus macaques. Psychosomatic Medicine 37: 50-61.

Sapolsky RM (1983). Endocrine aspects of social instability in the olive baboon (Papio anubis). American Journal of Primatology 5: 365-379.

Sapolsky RM (1993). The physiology of dominance in stable versus unstable social hierarchies. In Primate Social Conflict (Mason WA, Mendoza SP, eds.), pp 171-204. Albany, SUNY Press.

Sapolsky RM (2005). The influence of social hierarchy on primate health. Science 308: 648-652.

Schoof VAM, Jack KM (2009). Rank-based differences in fecal androgen and cortisol levels in male white-faced capuchins, Cebus capucinus, in the Santa Rosa Sector, Area de Conservacíon Guanacaste, Costa Rica (abstract). Am Soc Primatol Annu Meet, San Diego, September 18-21, 2009.

Setchell JM, Dixson AF (2001). Changes in the secondary sexual adornments of male mandrills (Mandrillus sphinx) are associated with gain and loss of alpha status. Hormones and Behavior 39: 177184.

Setchell JM, Smith T, Wickings EJ, Knapp LA (2008). Social correlates of testosterone and ornamentation in male mandrills. Hormones and Behavior 54: 365-372.

Van Hooff JARAM (2004). Relationships among non-human primate males: a deductive framework. In Primate Males: Causes and Consequences of Variation in Group Composition (Kappeler PM, ed.), pp 183-191. Cambridge, Cambridge University Press.

-Wickings EJ, Dixson AF (1992). Testicular function, secondary sexual development, and social status in male mandrills (Mandrillus sphinx). Physiology and Behavior 52: 909-916.

Wingfield JC, Hegner RE, Dufty AMJ, Ball GF (1990). The 'challenge hypothesis': theoretical implications for patterns of testosterone secretion, mating systems, and breeding strategies. American Naturalist 136: 829-846. 